\title{
THE ELECTRICAL CONDUCTIVITY OF
}

\section{SINGLE-CRYSTAL CERIOM DTOXIOE*} F. S. Brugner and R. N. Bl umenthal
Metal lurgy and Materials Science, Col lege of Engineering Marquette University, Milwaukee, Wisconsin 53233

Cerium dioxide has been the subject of several electrical conductivity investigations. ${ }^{1-7}$ Although $\mathrm{Ce}_{1+y} \mathrm{O}_{2}$ is thermodynamically stable over a wide range of oxygen pressures and temperatures $\left(e . g . \mathrm{Ce}_{1+y} \mathrm{O}_{2}\right.$ is thermodynamically stable ${ }^{8}$ to values of $\mathrm{P}_{2}$ as low as $10^{-20}$ atm at $1023^{\circ} \mathrm{C}$ ) most of the electrical conductivity investigations ${ }^{1-5}$ on $\mathrm{Ce}_{1+y} \mathrm{O}_{2}$ have been limited to the oxygen pressure region 1 to $10^{-4}$ atm. In order to help elucidate the nonstoichlometric defect structure in $\mathrm{Ce}_{1+y} \mathrm{O}_{2}$, work was initiated in this laboratory on the electrical conductivity of $\mathrm{Ce}_{1+y_{2}} \mathrm{O}_{2}$ as a function of temperature and oxygen partial pressure from $800^{\circ}$ to $1500^{\circ} \mathrm{C}$ and from 1 to $10^{-21}$ atm of oxygen: 6,7 in these studies only sintered specimens of $\mathrm{Ce}_{1+y} \mathrm{O}_{2}$ were used since single crystals were not available. Recently, small single crystals of $\mathrm{CeO}_{2}$ have been grown in our laboratories using an open system vapor transport technique. 9 The electrical conductivity of one of these crystals has been measured as a function of temperature and oxygen pressure using the same experimental apparatus and technique as described previously. $6,7,10$ These results are shown in Fig. I as isothermal plots of $\log \sigma$ vs $\log \mathrm{P}_{\mathrm{O}_{2}}$. The conductivity data obtained from sintered specimens has been normalized for porosity using the simple relationship

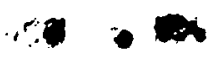

$$
\sigma_{\text {normalized }}=\sigma_{\text {measured }} \frac{\rho_{\text {theoretical }}}{\rho_{\text {measured }}}
$$

*This work was supported by the U.S. Atomic Energy Commission. This is AEC Report COO-1441-11. 


\section{DISCLAIMER}

This report was prepared as an account of work sponsored by an agency of the United States Government. Neither the United States Government nor any agency Thereof, nor any of their employees, makes any warranty, express or implied, or assumes any legal liability or responsibility for the accuracy, completeness, or usefulness of any information, apparatus, product, or process disclosed, or represents that its use would not infringe privately owned rights. Reference herein to any specific commercial product, process, or service by trade name, trademark, manufacturer, or otherwise does not necessarily constitute or imply its endorsement, recommendation, or favoring by the United States Government or any agency thereof. The views and opinions of authors expressed herein do not necessarily state or reflect those of the United States Government or any agency thereof. 


\section{DISCLAIMER}

Portions of this document may be illegible in electronic image products. Images are produced from the best available original document. 


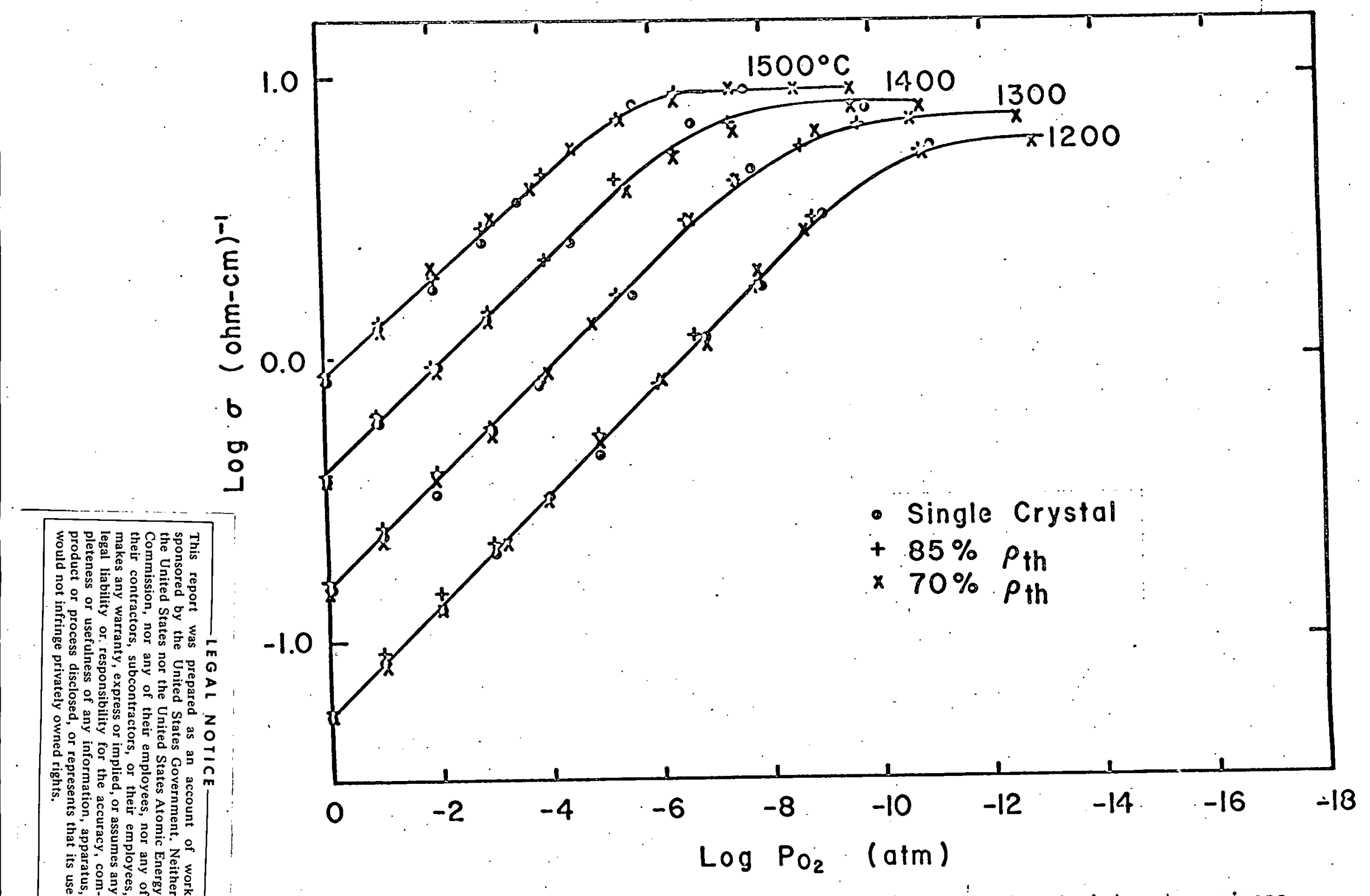

Fig. I Isothermal plots of $\log \sigma$ vs $\log P_{O_{2}}$ for single crystal and sintered specimens of $\mathrm{Ce}_{\mathrm{O}_{2}}$. The conductivity of $\mathrm{O}_{2}$ the sintered specimens has been normalized using 'ty. ${ }^{2}(1)$ : 
where $\rho_{\text {measured }}$ is the density of the sintered specimen. For comparative purposes the normalized conductivity values of $70 \%$ and $85 \%$ dense sintered specimens are also shown in Fig. 1 .

The agreement between the normalized conductivity values and the single crystal data in the temperature range $1200^{\circ}-1500^{\circ} \mathrm{C}$ is excellent. Only the data above $1200^{\circ} \mathrm{C}$ is shown here because the impurities present in the single crystal influence the magnitude of the conductivity below $1200^{\circ} \mathrm{C}$, particularly at high oxygen pressures.

The reason that the conductivity of the sintered specimens may be corrected for porosity by using such a simple expression as Eq. (1) is that the electron mobility ${ }^{\prime \prime}$ is small $\left(210^{-2} \mathrm{~cm}^{2} y\right.$ volt-sec), thus any additional scattering due to the porosity and grain boundarles is negligible. An important observation to be made is that the conductivity of single crystal $\mathrm{Ce}_{1+y} \mathrm{O}_{2}$ may be calculated by multiplying the conductivity of sintered specimens by a simple constant (i.e. $\frac{\rho_{\text {theoretical }}}{\rho_{\text {measured }}}$ which is independent of temperature and oxygen pressure.

Recently, the enthalpies of the nonstoichiometric defect reactions ${ }^{7}$ and the activation energy for electron motion 11 of $\mathrm{Ce}_{1}{ }_{1+y} \mathrm{O}_{2}$ have been calculated using the conductivity data and thermogravimetric data obtained from sintered samples. If single crystal data were used in these analyses the same results would be obtained, since these analyses depend only on the relative change of the conductivity with temperature and oxygen pressure. 


\section{REFERENCES}

1. J. Rudolph, Z. Naturforschg., 14a, 727 (1959).

2. E. H. Greener, J. M. Wimmer and W. M. Hirthe, Rare Earth Research 11, edited by Kari S. Vorres, Gordon and Breach, New York, 1964, p. 539.

3. C. J. Kevane, Phys. Rev., 133, Al431 (1964).

4. C. J. Kevane, E. L. Holverson and James B. Armstrong, presented at the Fifth Rare Earth Research Conference, Ames, lowa, August 1965.

5. 1. V. Vinokurov, Z. N. Zonn, and V. A. loffe, Soviet Physics-Solid State, $\underline{9}, 2659$ (1968).

6. R. N. Blumenthal and J. E. Laubach, Anisotropy in Single-Crystal Refractory Compounds, Vol. 2, Plenum Press, New York, 1968, p. 137.

7. R. N. Blumenthal, P. W. Lee and R. J. Panlener, to be published J. Electrochem. Soc.

8. D. J. M. Bevan and J. Kordis, J. Inorg. Nucl. Chem., 26, 1509 (1964).

9. W. M. Hirthe, R. N. Blumenthal and M. A. Seitz, Technical Progress Report No. 3, Advanced Research Projects Agency (1970).

10. R. N. Blumenthal, J. Coburn, J. Baukus and W. M. Hirthe, J. Phys. Chem. Sol ids, 27, 643 (1966).

11. R. N. Blumenthal and R. J. Panlener, J. Phys. Chem. Solids, 31, 1190 (1970). 